\title{
Palmeiras (Arecaceae) das Restingas do Estado do Rio de Janeiro, Brasil ${ }^{1}$
}

\author{
Ricardo Carneiro da Cunha Reis ${ }^{2}$
}

recebido em 9/11/2004 Aceito em 6/12/2005

\begin{abstract}
RESUMO - (Palmeiras (Arecaceae) das Restingas do Estado do Rio de Janeiro, Brasil). Neste trabalho foram coletadas, identificadas e sistematizadas as palmeiras das restingas do estado do Rio de Janeiro. Para a coleta de material, foram eleitas cinco estações de coleta consideradas representativas em termos de ocorrência de palmeiras. Foram identificadas 11 espécies, as quais podem ser reconhecidas pelo uso da chave dicotômica fornecida, e confirmadas pelas descrições e fotos apresentadas. O tratamento taxonômico das espécies encontra-se complementado por informações de distribuição geográfica, ecologia, nomes vulgares, e listas dos espécimes de herbário examinados.
\end{abstract}

Palavras-chave: Palmeiras, Arecaceae, restinga, Rio de Janeiro

ABSTRACT - (Palms (Arecaceae) from the restingas of Rio de Janeiro State, Brazil). Palms of the restingas of Rio de Janeiro State were collected, identified and treated taxonomically. The plants were collected at five sites that are representative in terms of palm species occurrence. The 11 species can be identified using the dichotomous key and confirmed using descriptions and photos. The taxonomic treatment is accompanied by additional information on geographic distribution, ecology, common names, and lists of herbarium specimens examined.

Key words: Palms, Arecaceae, restinga, Rio de Janeiro

\section{Introdução}

As restingas foram incluídas por Veloso et al. (1991) em uma categoria a qual chamaram de "Sistema edáfico de primeira ocupação" ou "Formações pioneiras", juntamente com as vegetações dos manguezais, dos brejos, pântanos e áreas ribeirinhas, e sendo tratada, então, sob o nome específico de "Vegetação com influência marinha".

Sabe-se que a delimitação precisa do que seja uma restinga consiste em tarefa algo complexa, haja visto a diversidade dos conceitos populares e científicos historicamente adotados. A vegetação que ocupava as planícies costeiras no passado era representada por uma massa verde contínua, apenas interrompida ocasionalmente por dunas e afloramentos rochosos próximos ao mar (Ule 1901). Entretanto, atualmente as restingas estão representadas por um conjunto reduzido e descontínuo de manchas de vegetação, o que dificulta ainda mais a elaboração de um conceito definitivo para as mesmas. A origem deste ecossistema está relacionada a fenômenos geológicos sedimentares e ao regime de marés de cada local. No Rio de Janeiro, muitas vezes assumem a forma de extensas planícies como em Macaé e Carapebus, grandes dunas como na restinga de Massambaba, ou braços de terra que avançam mar adentro como na restinga de Marambaia, juntas chegando a ocupar uma área correspondente a cerca de $1.200 \mathrm{~km}^{2}$ (Araújo \& Maciel 1998). Entretanto, todas possuem em comum o fato de terem surgido aproximadamente no período quaternário, após a última regressão marinha, e de terem sido colonizadas por flora e fauna que em grande parte, são provenientes da Mata Atlântica vizinha (Araújo \& Lacerda 1987).

Nas planícies costeiras onde encontram-se as restingas, destaca-se uma faixa continental adjacente às encostas da Serra do Mar, onde hoje predominam áreas ocupadas por fazendas, sítios, condomínios, etc. Esta faixa, estima-se, já esteve no passado coberta principalmente por matas secas de restinga, mas hoje caracteriza-se por campos quase completamente desmatados e representa uma barreira para a troca de material genético que outrora devia ocorrer livremente entre a restinga e as matas das encostas (Araújo \& Lacerda 1987). Na faixa mais próxima ao mar ainda existem alguns trechos preservados, sendo o mais representativo o do "Parque Nacional da Restinga de Jurubatiba", no norte do estado.

Muitos trabalhos florísticos e fitossociológicos vêm sendo realizados nas diversas restingas da costa

1 Parte da Dissertação de Mestrado do Autor, Museu Nacional, UFRJ, Bolsista de Pós-Graduação da Capes

2 Convênio BBM/JBRJ - Instituto de Pesquisas Jardim Botânico do Rio de Janeiro - DIPEQ - Programa Protaxon (ricardo@jbrj.gov.br) 
fluminense (Araújo \& Henriques 1984; Araújo et al. 2001), e também alguns trabalhos dedicados a ecologia de populações e de comunidades vegetais (Araújo et al. 1998). Dando continuidade aos estudos sobre essa vegetação, apresenta-se neste trabalho o resultado de uma análise florística e taxonômica das Arecaceae das restingas do Estado do Rio de Janeiro.

Para a contextualização das Arecaceae dentro dos grandes grupos taxonômicos, baseou-se em Uhl \& Dransfield (1987). Estes autores citam Principes como o nome original da ordem monofamiliar que engloba as palmeiras, e sugerem Arecales como o nome alternativo. Para a família, citam Palmae como o nome original a ser conservado pelo uso e Arecaceae como nome alternativo que também deve ser conservado. $\mathrm{O}$ sistema proposto por estes mesmos autores, prevê a divisão das Arecaceae em seis subfamílias. Dessas, apenas a sub-família Arecoideae encontra-se representada nas restingas fluminenses.

\section{Material e métodos}

Para a amostragem dos dados, foram eleitas cinco estações de coleta. Tais estações compreendem as principais unidades de conservação de restinga do litoral fluminense, e também outras áreas com remanescentes significativos desse tipo vegetacional. As estações são: 1) Macaé $\left(22^{\circ} 22^{\prime} \mathrm{S} ; 41^{\circ} 47^{\prime} \mathrm{W}\right)$; 2 ) Cabo Frio ( $22^{\circ} 34^{\prime} \mathrm{S}$;

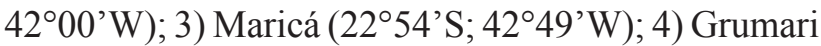

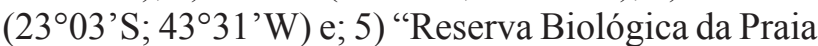

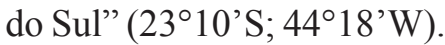

A escolha destas áreas como estações de coleta baseou-se principalmente em um levantamento prévio das informações contidas nas etiquetas dos materiais dos herbários RB, R, HB, GUA e RUSU, as quais permitiram indicar as áreas com maior probabilidade de ocorrência de palmeiras. Também foi levado em consideração a extensão e o nível de preservação das áreas

As expedições de coleta foram efetuadas mensalmente entre janeiro/1998 e março/1999, tendo-se percorrido as áreas segundo transectos no sentido praia-continente, visando abranger o maior número possível de comunidades vegetais. Os materiais coletados foram fotografados, processados e depositados no Herbário do Museu Nacional (R).
As descrições taxonômicas foram baseadas preferencialmente na análise de amostras frescas no campo, tendo sido complementadas com a análise de materiais depositados nos herbários supracitados.

Alguns caracteres tradicionalmente abordados por muitos autores nas descrições e/ou chaves dicotômicas relativas a palmeiras (Henderson \& Galeano 1996; Moraes 1996; Henderson 2000) não foram utilizados no presente conjunto de descrições, pois são comuns a todos os taxa abordados. São eles: 1 - plantas monóicas; 2 - folhas pinadas; 3 - porção basal das inflorescências andróginas com flores dispostas em tríades, sendo a flor central feminina e séssil, e as duas laterais masculinas e pediceladas.

A identificação dos materiais coletados fundamentou-se na comparação com os materiais de herbário e da consulta de bibliografias de referência (Martius 1823-1850; Drude 1881-1882; Barbosa Rodrigues 1903; Fernandes 1984; Glassman 1987, 1999; Uhl \& Dransfield 1987; Henderson 1995; 2000; Henderson et al. 1995; 1996).

Os dados de distribuição geográfica, ecologia e nomes populares, foram obtidos principalmente através de informações oriundas de herbários e de bibliografia, mas também a partir das observações feitas em campo e das informações cedidas pelos habitantes nativos das diversas localidades.

\section{Resultados}

Foram encontradas, ao longo das seis estações de coleta, 11 espécies de Arecaceae, pertencentes aos seguintes gêneros: Allagoptera, Astrocaryum, Attalea, Bactris, Desmoncus, Euterpe, Geonoma, Polyandrococos e Syagrus.

A grande maioria dos exemplares observados encontrava-se em áreas de mata de restinga, sendo mais frequente a ocorrência em matas submetidas a algum grau de inundação. A palmeira mais avistada foi Allagoptera arenaria, cujos grandes adensamentos motivaram a criação da "Comunidade Arbustiva de Palmae" proposta por Araújo et al. (1998). As restingas do nordeste do estado possuem visualmente uma maior quantidade de espécimes por área, e também a maior diversidade de espécies de Arecaceae em todo o estado.

Chave para identificação das espécies

1. Plantas com espinhos emergentes no estipe, dispostos de maneiras variadas

2. Palmeiras lianescentes; raque foliar estendendo-se em um cirro provido de acantófilos 
3. Bainha foliar 35-40 cm compr.; raque foliar 0,8-2 $\mathrm{m}$ compr., com espinhos eretos de 4-7 cm compr.; inflorescência com 25-30 ráquilas

6. Desmoncus orthacanthos

3. Bainha 20-25 cm compr.; raque foliar 40-90 cm compr. com espinhos ungüiculados de até 1,5 cm compr.; inflorescência com 10 -16 ráquilas 7. Desmoncus polyacanthos

2. Palmeiras nunca lianescentes; raque foliar desprovida de cirros e de acantófilos

4. Estipe 1,6-7 cm de diâmetro, com espinhos até $8 \mathrm{~cm}$ de compr., teretes

5. Bainhas foliares frequentemente marcescentes; pinas glaucas na face abaxial ... 5. Bactris vulgaris

5. Bainhas foliares raramente marcescentes; pinas nunca glaucas

4. Bactris setosa

4. Estipe 12-15(18) cm de diâmetro, com espinhos de 10-18 cm compr., achatados

2. Astrocaryum aculeatissimum

1. Plantas inermes

6. Estipe geralmente subterrâneo, raramente aflorando alguns centímetros sobre o solo

7. Raque foliar 0,5-0,83(1,2) m compr.; pinas 35-53 em cada lado da folha, dispostas em planos variados, agrupadas na raque em feixes de 1-4 pinas 1. Allagoptera arenaria

7. Raque foliar 1,8-3,6 m compr.; pinas 88-120 em cada lado da folha, dispostas em um único plano, regularmente distribuídas ao longo da raque 3. Attalea humilis

6. Estipe aflorando nitidamente sobre o solo

8. Bainha 1-1,5 m compr., tubular, formando um capitel distinto; inflorescência infra-foliar

8. Euterpe edulis

8. Bainha inferior a $0,6 \mathrm{~m}$ compr., nunca formando um capitel, inflorescência interfoliar

9. Estipe 4,2-5,9 cm de diâmetro; pecíolo $60-98 \mathrm{~cm}$ compr. 9. Geonoma schottiana

9. Estipe acima de $15 \mathrm{~cm}$ de diâmetro; pecíolo inferior a $60 \mathrm{~cm}$ compr.

10. Pinas dispostas em um único plano, regularmente distribuídas ao longo da raque; inflorescência espiciforme

10. Polyandrococos caudescens

10. Pinas dispostas em vários planos, distribuídas na raque em grupos de 2-5; inflorescência ramificada nunca espiciforme 11. Syagrus romanzoffiana

1. Allagoptera arenaria (Gomes) Kuntze, Revis. Gen. P1. 2: 726. 1891.

Fig. 1-2

Nomes populares: buri, buri-da-praia, buriri, caxandó, coco-da-praia, guriri, pissandó.

Planta com 1-2,5 m alt. Estipe ca. $10 \mathrm{~cm}$ de diâmetro, normalmente indiviso e subterrâneo, raramente ramificado e/ou aflorando alguns centímetros sobre o solo. Folhas 6-10; pecíolo 45-80(-100) cm compr.; raque 50-83(-120) cm compr.; pinas 35-53 em cada lado da folha, dispostas em planos variados, agrupadas na raque em feixes de 1-4 pinas, linear-lanceoladas; pinas medianas 20-45×1,1-2 cm. Inflorescência normalmente hermafrodita, raro exclusivamente estaminada, sempre espiciforme; bráctea peduncular $60-80 \mathrm{~cm}$ compr., até $6 \mathrm{~cm}$ larg., lenhosa; raque $10-15 \mathrm{~cm}$ compr. Flores estaminadas com pedicelos até $4 \mathrm{~mm}$ compr.; sépalas e pétalas coriáceas, glabras; estames 10-18, conados na base; anteras sagitadas; pistilódio rudimentar ou ausente. Flores pistiladas sésseis; sépalas e pétalas papilosas na margem, rostradas; ovário 1,2-1,3 mm compr., glabro; estigmas sésseis; estaminódios unidos formando um anel. Fruto 1,2-2×1-1,3 cm, obovóide. Semente geralmente 1, raro 2 ou 3; endosperma homogêneo.

Distribuição e ecologia: planta tipicamente heliófila, endêmica das restingas da costa leste do Brasil. Ocorre desde Pernambuco até o Paraná (Henderson et al. 1995; Moraes 1996). No Estado do Rio de Janeiro ocorre em todas as restingas de norte a sul, desde as mais preservadas até as mais impactadas. Possui uma peculiar capacidade de sobreviver ao fogo, rebrotando a partir dos estipes rizomatosos subterrâneos (Araújo \& Peixoto 1977). Allagoptera arenaria parece mais bem adaptada às áreas abertas, onde os solos são de natureza arenosa-silicosa (Araújo et al. 1998). Entretanto observou-se alguns espécimes nas comunidades arbustivas fechadas e nas matas de restinga, submetidos a um maior sombreamento e a solos mais ricos em matéria orgânica e umidade, onde mostravam-se mais robustos e chegavam a ultrapassar os $2 \mathrm{~m}$ de altura.

Material selecionado: BRASIL. Rio de Janeiro: Arraial do Cabo, 29/VII/1992, fl., R.C. Lopes 30 et al. (RUSU); Búzios, 22/V/1985, fl.fr., D.S.D. de Araújo 6911 (GUA); Cabo Frio, 29/VIII/1986, fl.fr., D.S.D. 
de Araújo 7547 et al. (GUA); Carapebus, 8/X/1996, fr., L. Heron 61 et al. (HB); Maricá, 23/IX/1988, fr., D.S.D. de Araújo 8568 et al. (GUA); Rio de Janeiro, 6/V/1992, fl., J.M.A. Braga 12 et al. (RUSU); Idem, 5/IX/1962, fr., E. Santos 1266 et al. (HB); São João da Barra, 12/I/1982, D.S. Souza 561 et al. (GUA); Saquarema, 27/X/1963, fl.fr., L.F. Pabst s.n. (HB).

2. Astrocaryum aculeatissimum (Schott) Burret, Repert. Spec. Nov. Regni Veg. 35: 152. 1934.

Fig. 3

Nomes populares: brejaúba, brejaúva, coqueirobrejaúba, iri, tucum, tucum-verdadeiro.

Planta com 5-10 m alt., cespitosa. Estipes (1)2-7, 12-15(18) cm de diâmetro, densamente recobertos por espinhos de 10-18 cm compr., achatados. Folhas 5-8; bainha ca. $25 \mathrm{~cm}$ compr., aberta, densamente recoberta por espinhos negros, achatados, maiores que os dos estipes; pecíolo 1-1,2 m compr., irregularmente espinescente; raque 3-3,7 m compr., regularmente espinescente; pinas dispostas em um único plano, regularmente distribuídas ao longo da raque, lanceoladas, verde-escuras na face adaxial, tipicamente glaucas na face abaxial. Inflorescência hermafrodita interfoliar, ramificada até $1^{\mathrm{a}}$ ordem; bráctea peduncular 60-85 cm compr., até $23 \mathrm{~cm}$ larg., coriácea a lenhosa; raque $37-48 \mathrm{~cm}$ compr., esparsamente espinescente ou inerme. Fruto 6-7×4-5 cm, obovóide, rostrado, marrom quando maduro; epicarpo revestido por pêlos acastanhados, finos e rígidos. Semente 1; endosperma homogêneo.

Distribuição e ecologia: ocorre desde a Bahia até Santa Catarina, sempre associada a mata atlântica (Henderson et al. 1995; Lorenzi et al. 2004). No Rio de Janeiro, observou-se que nas áreas associadas a topos de morros (altos), onde normalmente os solos são mais bem drenados, os espaçamentos entre indivíduos são sempre maiores e em geral, as palmeiras apresentam pequeno porte, por vezes passando anos sem emitir um caule nítido sobre o solo. Nas áreas associadas a vales, onde o solo em geral acumula uma maior umidade, os indivíduos são bem mais freqüentes e avantajados, podendo ultrapassar os $8 \mathrm{~m}$ de altura.

Material selecionado: BRASIL. Rio de Janeiro: Angra dos Reis, 14/VI/1984, estéril, H.Q.B. Fernandes 937 et al. (GUA); Macaé, 24/VIII/1982, fr., D.S.D. de Araújo 5211 et al. (GUA).

3. Attalea humilis Mart. Ex Spreng., Syst.Veg. 2: 624. 1825.

Fig. 4
Nomes populares: anajá-mirim, catolé, cococatolé, coco-de-pindoba, indaiá-mirim, pindoba.

Planta com 1,2-3,1 m alt. Estipe solitário, geralmente subterrâneo, raro aflorando alguns centímetros sobre o solo. Folhas 8-12; pecíolo 47-75 cm compr.; raque 1,80-3,60 m compr.; pinas 88-120 em cada lado da folha, dispostas em um único plano, regularmente distribuídas ao longo da raque, lineares, concolores; pinas medianas 65-95× 3,5-5,5 cm. Inflorescências estaminadas e hermafroditas interfoliares, ramificadas até $1^{\mathrm{a}}$ ordem; brácteas pedunculares $50-71 \mathrm{~cm}$ compr., até $18 \mathrm{~cm}$ larg., rostradas; raques $24-41 \mathrm{~cm}$ compr. Flores estaminadas curto-pediceladas; sépalas e pétalas coriáceas, glabras; estames 6; filetes até $3 \mathrm{~mm}$ compr.; anteras 7-12 mm compr.; pistilódio rudimentar ou ausente. Flores pistiladas sésseis; sépalas coriáceas, glabras; pétalas coriáceas a córneas, glabras; ovário ca. $1 \mathrm{~cm}$ compr.; estigmas 3 , até $1 \mathrm{~cm}$ compr., sésseis ou sobre um curto estilete; anel estaminodial ca. $0,5 \mathrm{~cm}$ compr. Fruto $5-8 \times 3,5-6,1 \mathrm{~cm}$, globoso a obovóide, marrom quando maduro. Sementes 1-3; endosperma homogêneo.

Distribuição e ecologia: segundo Lorenzi et al. (2004), esta espécie ocorre desde a Bahia até São Paulo. Glassman (1999) sugere São Sebastião do Passé, na Bahia, como sendo o ponto norte mais extremo da distribuição da espécie. Apesar de sua presença marcante no Rio de Janeiro, com muitos indivíduos crescendo tanto nas matas de restinga quanto nas encostas de mata atlântica, ora em formações gregárias ora isoladas, a espécie ocorre com maior abundância nas serras declivosas de Mata Atlântica da faixa costeira do Estado da Bahia (Noblick 1991; Glassman 1999). Nas encostas florestadas, onde os solos são úmidos e férteis, porém bem drenados, a espécie atinge um maior porte, podendo cada folha apresentar até $5 \mathrm{~m}$ de comprimento. Nas matas secas de restinga as populações são mais densas e os indivíduos são em geral menores, diminuindo sua quantidade e seu tamanho conforme se aproximam das matas alagadas. Já nas encostas nuas e ensolaradas na beira das estrada, onde Duarte (1981) afirma que são comuns, apresentam-se anãs, formando populações numerosas com indivíduos de folhas freqüentemente amareladas.

Material selecionado: BRASIL. Rio de Janeiro: Carapebus, 4/VII/1999, fl./fr., R.C.C. Reis 222 \& M. Guerra (R); Macaé, 27/X/1985, fr., D.S.D. de Araújo 7084 et al. (GUA); Rio das Ostras, 13/VI/1982, fl., H.Q.B. Fernandes 472 (GUA). 

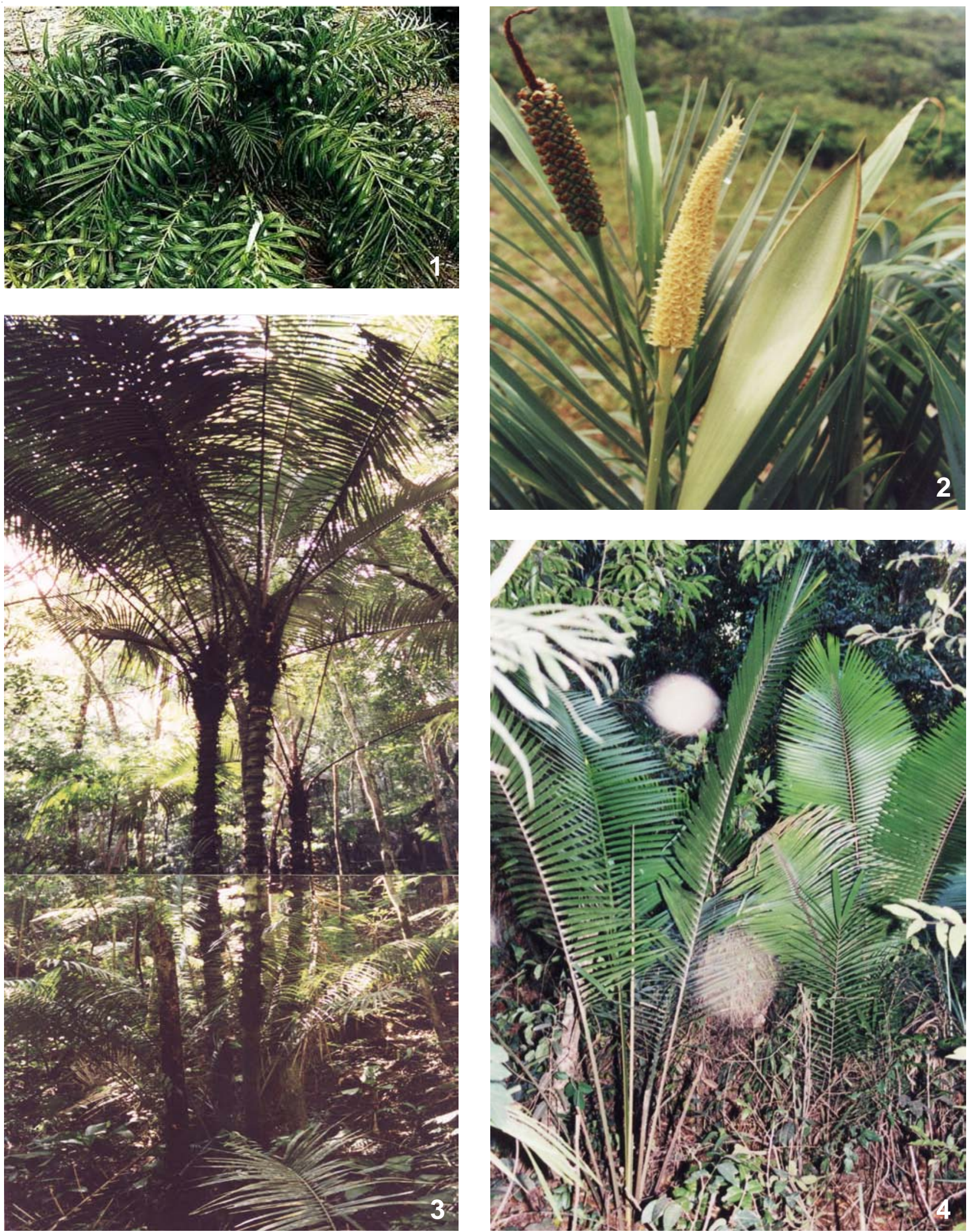

Figuras 1-2. Allagoptera arenaria (Gomes) Kuntze. 1. Hábito de um indivíduo adulto, Maricá. 2. Inflorescências em diferentes estágios de desenvolvimento, restinga de Grumari, Rio de Janeiro. Figura 3. Astrocaryum aculeatissimum (Schott) Burret - indivíduo adulto na mata do $2^{\circ}$ cordão arenoso, Parque Nacional da Restinga de Jurubatiba (PNRJ), Carapebus. Figura 4. Attalea humilis Mart. ex Spreng. - indivíduos adultos na borda da mata do $2^{\circ}$ cordão arenoso, PNRJ, Carapebus. 
4. Bactris setosa Mart., Hist. Nat. Palm. 2: 94, t.72, fig. 1-3. 1826.

Fig. 5-7

Nomes populares: coco-de-natal, coco-de-tucum, tucum (nome mais comum), tucum-bravo, tucum-dobrejo, uva-do-mato, uva-da-terra.

Planta com 2,8-5,6(8,0) $\mathrm{m}$ alt., cespitosa. estipes até $15,(2,5) 3-7 \mathrm{~cm}$ de diâmetro, densamente recobertos por espinhos negro-acinzentados, até $8 \mathrm{~cm}$ compr., teretes. Folhas 3-8; bainha 20-66 cm compr., aberta, por vezes 1-2 marcescentes; pecíolo 12-110 cm compr., regularmente a irregularmente espinescente; raque 0,69-2,29 m compr., regularmente a irregularmente espinescente; pinas 13-66 em cada lado da folha, dispostas em um ou mais planos, regularmente distribuídas a agrupadas em feixes de 2-8 pinas, lineares a linear-oblanceoladas, concolores. Inflorescência hermafrodita interfoliar, bráctea peduncular $28-75 \mathrm{~cm}$ compr., coriácea, rostrada; raque 2,2-34 cm compr. Flores estaminadas com sépalas e pétalas membrano-carnosas; estames adnatos a corola, filete 1,4-4,4 mm compr., antera 1,5-2,8 mm compr.; pistilódio ca. $0,6 \mathrm{~mm}$ compr. Flores pistiladas com ovário ovóide a globoso; estiletes 3, conados na base; estigmas truncados, glabrescentes; estaminódios adnatos a corola. Fruto 1,2-2,1×1,3-2,4 cm, negro-arroxeado a marrom-escuro quando maduro.

Distribuição e ecologia: ocorre desde Piauí e Pernambuco até o Rio Grande do Sul. No Estado do Rio de Janeiro exemplares de B. setosa foram vistos em todas as restingas percorridas, tanto nas matas secas como nas alagadas. Predomina nitidamente nas restingas, sendo encontrada em populações menores em outros ecossistemas, já tendo sido avistada em altitudes até ca. de 1.000 m.s.m. (Fernandes 1995). $B$. setosa desenvolve-se melhor em locais alagadiços, onde produz touceiras mais densas, caules com entrenós curtos e raque foliar com espinhos mais estreitos, longos e escuro-amarelados. Já em lugares de solo mais seco costuma apresentar touceiras menos volumosas, com entrenós mais alongados, folhas mais curtas e raque foliar com espinhos de menor comprimento, alargados, semi-achatados e de coloração escura brilhante. De todas as espécies do gênero Bactris endêmicas de mata atlântica, é a que apresenta distribuição total mais ampla (Fernandes 1995).

Material selecionado: BRASIL. Rio de Janeiro: Angra dos Reis, 14/VI/1984, H.Q.B. Fernandes 939 et al. (GUA); Arraial do Cabo, 27/X/1993, fr., D.S.D. de Araújo 9930 (GUA); Cabo Frio, 24/IV/1979, fr., J.P.P. Carauta 3092 (GUA); Carapebus, 14/VII/1995, fr., D.S.D. de Araújo s.n. et al. (RB); Itaguaí, 19/II/1962, G.F.J. Pabst 6809 (HB); Macaé, 22/IX1981, D.S.D. de Araújo 4588 \& N.C. Maciel (GUA); Quiçamã, 14/V/1999, R.C.C. Reis 207 et al. (R); Rio de Janeiro, 9/VI/1969, fl., D. Sucre 5244 et al. (RB); idem, 29/XII/1963, fr., J.P. Lanna Sobrinho 548 (GUA); Saquarema, 22/XI/1986, fr., C. Farney 1258 et al. (RB); idem, 9/IV/1988, fl., D.S.D. de Araújo 8553 et al. (GUA).

5. Bactris vulgaris Barb. Rodr., Prot. Append. 42. 1879.

Fig. 8-9

Nomes populares: iri-mirim, tucum, tucum-mirim, tucum-preto.

Planta cespitosa geralmente de caules curtos, ocasionalmente alguns caules desenvolvendo-se até 4,5 $\mathrm{m}$ alt. Estipes até 25, 1,6-3,4 cm de diâmetro, recobertos por espinhos castanho-nigrescentes, até $6,5 \mathrm{~cm}$ compr., teretes. Folhas 6-8; bainha 19-50 cm compr., aberta, densamente espinescente, em geral várias marcescentes; pecíolo 28-157 cm compr., irregularmente espinescente; raque 50-264 cm compr., irregularmente espinescente ou inerme; pinas 13-42 em cada lado da folha, freqüentemente dispostas em um único plano, por vezes divergentes, regularmente arranjadas a agrupadas em feixes de 2-7 pinas, lineares, face adaxial verde-escura a verde-clara, face abaxial glauca. Inflorescência hermafrodita interfoliar; bráctea peduncular coriácea, rostrada. Flores estaminadas com sépalas e pétalas membranocarnosas; estames adnatos a corola a livres; pistilódio ausente. Flores pistiladas com ovário globoso a largamente obovóide; estiletes 3, conados na base; estigmas finamente pilosos; estaminódios adnatos a corola. Fruto largamente obovóide, negro-arroxeado quando maduro.

Distribuição e ecologia: ocorre desde a Bahia até São Paulo. Na Bahia, Lages (a sul de Salvador) é o município onde se registra a coleta mais ao Norte, enquanto que em Santos, São Paulo, encontramos o limite sul da distribuição (Fernandes 1995). No Rio de Janeiro ocorre nas matas de tabuleiro, nas florestas de encosta e também na restinga. Nesta última a espécie só foi encontrada na mata seca. Nas serras, ocorre até uma altitude de 700 m.s.m. Apesar de ser apontada por Barbosa Rodrigues (1879) como comum nas matas dos arredores do Rio de Janeiro, nas restingas a espécie mostrou-se de ocasional a rara.

Material selecionado: BRASIL. Rio de Janeiro: Carapebus, 4/VII/99, R.C.C. Reis 221 (R); Maricá, 

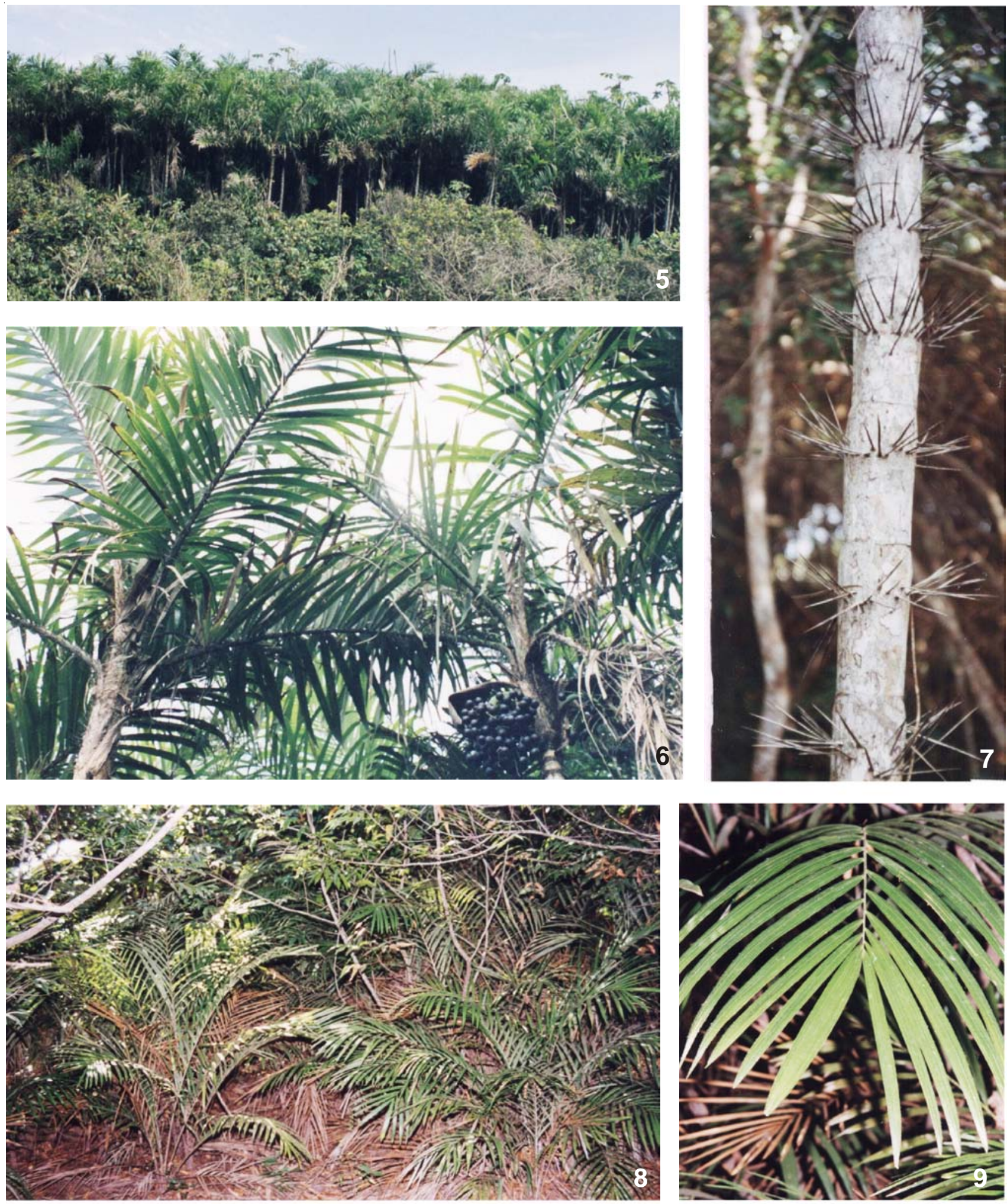

Figuras 5-7. Bactris setosa Mart. 5. Indivíduos na borda da mata periódicamente inundada do $1^{\circ}$ cordão arenoso, Parque Nacional da Restinga de Jurubatiba (PNRJ), Carapebus. 6. Dois indivíduos em destaque, um deles apresentando uma infrutescência. 7. Detalhe do estipe com espinhos. Figuras 8-9. Bactris vulgaris Barb. Rodr. 8. Dois indivíduos jovens em local sombreado, PNRJ, Carapebus. 9. Detalhe do ápice foliar. 
25/VI/1985, fr., D.S.D. de Araújo 6961 et al. (GUA); Saquarema, 16/IX/1992, D.S.D. de Araújo 9645 (GUA).

6. Desmoncus orthacanthos Mart., Hist. Nat. Palm. 2(3): 87, t. $69,98.1824$

Fig. 12

Nomes populares: cerca-onça, coco-de-cigano, jacitara, titara.

Planta lianescente, cespitosa. Caules 1-2 $\mathrm{cm}$ de diâmetro. Folha com bainha de $35-40 \mathrm{~cm}$ compr., tubular, espinescente; ócrea até $20 \mathrm{~cm}$ compr., espinescente; pecíolo 12-20 cm compr., esparsamente espinescente; raque $0,8-2 \mathrm{~m}$ compr., revestida por espinhos de $4-7 \mathrm{~cm}$ compr., eretos; cirro presente na porção distal da raque, provido de acantófilos; pinas 15-23 em cada lado da folha, irregularmente distribuídas ao longo da raque, lanceoladas a fusiformes. Inflorescência hermafrodita ramificada até $1^{\mathrm{a}}$ ordem; bráctea peduncular $50-60 \mathrm{~cm}$ compr.; raque tortuosa; ráquilas 25-30, freqüentemente partindo de uma curta raque, outras vezes dividindo-se diretamente a partir do pedúnculo. Flores estaminadas com pétalas longamente rostradas; estames 6 ; filetes conados; anteras 3-4 mm compr. Flores pistiladas com ovário ca. $4 \mathrm{~mm}$ compr., ovóide; estaminódios rudimentares, adnatos a corola. Fruto ca. 1,5×1,0 cm, geralmente oblongo a ovóide, por vezes ventricoso, rostrado, laranja a vermelho quando maduro. Semente 1 ; endosperma homogêneo.

Distribuição e ecologia: amplamente distribuída no Brasil e nos demais países da faixa tropical da América do Sul, vegetando não somente nas restingas, mas também na Mata Atlântica e na Floresta Amazônica. Também é encontrada no complexo do Pantanal, descendo continuamente desde a faixa Oeste da Amazônia e espalhando-se pelos diversos braços de mata que acompanham o contorno dos rios Amazônicos e do Rio Paraguai. Aparentemente encontra seu habitat ideal nas bordas degradadas dos diversos tipos de mata, muitas vezes comportando-se como invasora. Nas formações de matas continentais secas sua ocorrência passa a ser rara, e jamais foram vistas no sub-bosque de matas fechadas. Ocorre ainda, em todo o Brasil, por diversas áreas conturbadas com vegetação secundária (Wessels Boer 1965).

Nas restingas ocorre com freqüência nas bordas das matas secas até ca. de $8 \mathrm{~m}$ de altura, ou sob a forma de pequenos arbustos escandentes de até $2 \mathrm{~m}$ de altura. Porém, é nas bordas das matas inundadas que $D$. orthacanthos parece adaptar-se melhor, onde alcança alturas que ultrapassam os $15 \mathrm{~m}$.
Material selecionado: BRASIL. Rio de Janeiro: Carapebus, XII/1999, R.C.C. Reis 201 et al. (R); Macaé, 13/XII/1995, fl., D. Gonçalves 41 et al. (RB); Maricá, 11/IV/1986, fr., D.S.D. de Araújo 7352 (GUA); Rio de Janeiro, 22/III/1963, fr., J.P. Lanna Sobrinho 485 (GUA); idem, 13/XII/1962, fl., J.P. Lanna Sobrinho 513 (GUA); Saquarema, VIII/1998, R.C.C. Reis 191 et al. (R).

7. Desmoncus polyacanthos Mart., Hist. Nat. Palm. 2(3): $85-86$, t. 68.1824

Nomes populares: titára, jacitára, tipiti, coco-decigano, cerca-onça, capa-boi, salsa-de-bugre.

Planta lianescente, cespitosa. Caules 0,5-1,2 cm de diâmetro. Folhas com bainha de $20-25 \mathrm{~cm}$ compr., tubular, espinescente; ócrea 10-15 cm compr., geralmente espinescente, raro inerme; pecíolo $5-11 \mathrm{~cm}$ compr., espinescente; raque 40-90 cm compr., esparsamente revestida por espinhos de 1-1,5 cm compr., ungüiculados; cirro presente na porção distal da raque, provido de acantófilos; pinas 8-12 em cada lado da folha, regular ou irregularmente distribuídas ao longo da raque, lanceoladas a fusiformes. Inflorescência hermafrodita ramificada até $1^{\mathrm{a}}$ ordem; bráctea peduncular 48-55 cm compr.; raque curta, tortuosa; ráquilas 10-16. Flores estaminadas com cálice até 0,5 mm compr.; pétalas 5-6 mm compr.; estames 6 ; filetes conados; anteras ca. de $1 \mathrm{~mm}$ compr. Flores pistiladas curto-pediceladas ou sésseis; cálice ca. $1 \mathrm{~mm}$ compr.; corola ca. 1,5 mm compr.; ovário ca. 3,5 mm compr.; estaminódios muito reduzidos, adnatos a corola. Fruto oblongo a obovóide, curto-rostrado, amarelo a vermelho quando maduro. Semente 1; endosperma homogêneo.

Distribuição e ecologia: distribuição e ecologia praticamente idênticas as de D. ortacanthos, diferenciando-se apenas por esta última extender-se à Noroeste pelos países da América Central.

Material selecionado: BRASIL. Rio de Janeiro: Carapebus, 5/VI/1999, R.C.C. Reis 215 et al. (R); Casimiro de Abreu, 22/X/1983, estéril, H.Q.B. Fernandes 801 (GUA); Rio das Ostras, 13/VI/1982, fr., H.Q.B. Fernandes 469 (GUA).

8. Euterpe edulis Mart., Hist. Nat. Palm. 2: 33, t. 32. 1824.

Fig. 10-11

Nomes populares: jussara, juçara, jiçara, palmito, palmiteiro, palmito-juçara, palmito-doce.

Planta com 6-14(-18) $\mathrm{m}$ alt. Estipe 9-13(-15) cm de diâmetro, solitário. Folhas 8-15; bainha 1-1,5 m 
compr., tubular, formando um distinto capitel; pecíolo 21-50 cm compr.; raque 1,6-2,8 cm compr.; pinas 38-62(-70) em cada lado da folha, em geral dispostas em um único plano, raramente divergentes, regularmente sub-opostas na raque a agrupadas em feixes, lanceoladas, característicamente pêndulas; pinas medianas 49-80(-106)×1,5-4 cm. Inflorescência hermafrodita infra-foliar, ramificada até $1^{\mathrm{a}}$ ordem; bráctea peduncular 61-65(-104) cm compr.; raque 45-69 cm compr. Flores estaminadas sésseis; estames 6; filetes 1,5-2,3 cm compr., achatados; anteras 2,5-3 mm compr.; pistilódio ca. $1 \mathrm{~mm}$ compr. Flores pistiladas com sépalas e pétalas coriáceas, largoovadas; estaminódios ausentes. Fruto $1-1,4 \mathrm{~cm}$ de diâmetro, globoso, negro a denso-purpúreo quando maduro; epicarpo levemente ruguloso. Semente 1; endosperma homogêneo.

Distribuição e ecologia: Euterpe edulis ocorre desde a Bahia até o Rio Grande do Sul, distribuindo-se continuamente pelos estados da faixa costeira, sempre associada a mata atlântica (Mattos \& Mattos 1976; Henderson \& Galeano 1996; Lorenzi 2004). Em Minas Gerais, Distrito Federal, Mato Grosso, Mato Grosso do Sul e Goiás, também há registros de coletas, mas é no Rio Grande do Sul que a espécie demonstra uma exploração mais efetiva das faixas continentais, extendendo sua área de distribuição além da fronteira nacional e indo até o Paraguai e a Argentina (BarbosaRodrigues 1901; Reitz 1974). No Rio de Janeiro, ocorre principalmente nos vales e grotões úmidos das encostas de mata pluvial, mas também pode ser encontrada com relativa freqüência nas matas inundadas de restinga. Já na faixa interiorana, a espécie mostra-se restrita as áreas onde os solos possuem um maior teor de umidade, geralmente nas matas ciliares (Henderson \& Galeano 1996).

Originalmente as populações de E. edulis possuiam cerca de 1.000 exemplares/ha nas matas de encosta e até 100 exemplares/ha nas matas de restinga, contando-se apenas os indivíduos acima de 1,5 $\mathrm{m}$ de altura (Reitz 1974). Hoje, nas restingas fluminenses, dificilmente vê-se mais de 30 exemplares/ha.

Com relação a alta especificidade de habitat de E. edulis, Mattos \& Mattos (1976) emitem o seguinte comentário: "Tanto a ausência de água quanto a presença do solo do tipo arenoso, são prejudiciais ao desenvolvimento de E. edulis. Os solos encharcados e os de argila pesada também não são bons, pois são deficientes em aeração".

Material selecionado: BRASIL. Rio de Janeiro: Angra dos Reis, 14/VI/1984, estéril, H.Q.B.
Fernandes 933 et al. (GUA); Carapebus, 20/XII/1999, fl.fr., R.C.C. Reis 202 et al. (R); idem, 5/VI/1999, fr., R.C.C. Reis 213 et M. Guerra (R).

9. Geonoma schottiana Mart., Hist. Nat. Palm. 2: 143, t.11A. 1826

Fig. 13-15

Nomes populares: aricanga, aricanga-da-vargem, aricanga-do-brejo, guaricanga-de-folha-miúda, guaricanga-da-vargem, guaricanga, uricana.

Planta com 2-3,2(4) $\mathrm{m}$ alt. Estipe 4,2-5,9 $\mathrm{cm}$ de diâmetro, solitário. Folhas 6-15; bainha ca. $20 \mathrm{~cm}$ compr., aberta; pecíolo 60-98 cm compr.. Raque 52-93 cm compr.; 25-40 nervuras primárias em cada lado da folha, distribuídas em segmentos lineares com uma nervura primária cada um, estes dispostos em um único plano, distribuídos regularmente ao longo da raque, segmentos apicais diferenciados dos demais em forma e tamanho com até 4 nervuras primárias. Inflorescência hermafrodita interfoliar, até 2 por folha, ramificada até $2^{\mathrm{a}}$ ordem; bráctea peduncular tubulosa, subcoriácea; raque 12-25 cm compr.; ráquilas 7-17. Flores estaminadas sésseis; filetes muito delgados, alvos; anteras semi-globosas, amarelas. Flores pistiladas sésseis; estaminódios unidos formando um curto anel. Fruto $0,8-1 \mathrm{~cm}$ de diâmetro, aproximadamente globoso, por vezes curto-rostrado, negro quando maduro. Semente 1, ovóide; endosperma homogêneo.

Distribuição e ecologia: ocorre desde o Espírito Santo até Santa Catarina. Ocorre nas matas de restinga com certa irregularidade, estando totalmente ausente em alguns trechos e abundante em outros. Ocorre com maior freqüência e homogeneidade nas encostas de Mata Atlântica, podendo ocorrer em áreas até cerca de $1.000 \mathrm{~m}$ de altitude. Na restinga, esta planta está estreitamente relacionada com ambientes alagados, principalmente nas matas periódicamente inundadas, chegando a ser consideradas, em certos trechos, como espécie dominante do sub-bosque.

Material selecionado: BRASIL. Rio de Janeiro: Carapebus, 5/IX/1996, fl., R.C. de Oliveira s.n. et al. (RB); idem, XII/1999, R.C.C. Reis 200 et al. (R); Macaé, 2/VI/1981 (GUA); Quiçamã, 30/X/1994, fl.fr., C. Farney 3428 et al. (RB); Rio de Janeiro, 9/VI/1969, fr., D. Sucre 5247 et al. (RB); idem, 18/VII/1980, fl.fr., D.S. Souza 89 (GUA).

10. Polyandrococos caudescens (Mart.) Barb. Rodr., Contr. Jard. Bot. Rio de Janeiro. 1: 8. 1901.

Fig. 16 
Nomes populares: pati, palmito-amargoso, pindóba, buri, palha-branca, imburi.

Planta com 6-7 m alt. Estipe 15-25 cm de diâmetro, solitário. Folhas 6-11; bainha 35-40 cm compr., aberta; pecíolo 50-60 cm compr.; raque até $2 \mathrm{~m}$ compr.; pinas dispostas aproximadamente em um único plano, regularmente distribuídas ao longo da raque, lanceoladas, verde escuras na face adaxial, marcadamente glaucas na face abaxial. Inflorescência hermafrodita espiciforme; bráctea peduncular 90-120 cm compr., lenhosa, sutil a fortemente rostrada; pedúnculo distintamente fletido. Raque $45-50 \mathrm{~cm}$ compr. Flores estaminadas sésseis; sépalas fortemente rostradas; pétalas maiores que as sépalas; estames 96-100; filetes muito delgados; anteras 3-4 mm compr., lineares a ligeiramente sagitadas; pistilódio ausente. Flores pistiladas sésseis; ovário oval, tomentoso; estigmas sésseis, alongados; estaminódios unidos formando um anel. Fruto 4-5 cm compr., com formato irregular, em geral 2-lobado, achatado verticalmente, verde a marron quando maduro. Semente 1; endosperma homogêneo.

Distribuição e ecologia: ocorre desde Pernambuco até o Rio de Janeiro. Nas restingas do Rio de Janeiro ocorre mais restritamente nas matas secas mais afastadas do mar (mata de $2^{\circ}$ e $3^{\circ}$ cordão arenoso). Podem ser encontradas mais raramente em faixas mais interioranas, próximo à base das encostas florestadas. A representação da espécie nas restingas do estado mostrou-se muito reduzida, tendo sido avistadas pequenas populações apenas nos municípios de Cabo Frio e Rio das Ostras.

Material selecionado: BRASIL. Rio de Janeiro: Cabo Frio, 13/V/1999, R.C.C. Reis 206 et al. (R); idem, 14/I/1988, fr., D.S.D. de Araújo 8450 (GUA).

11. Syagrus romanzoffiana (Cham.) Glassman, Fieldiana, Bot. 31(17): 382. 1968

Fig. 17-18

Nomes populares: baba-de-boi, coco-de-cachorro, geribá, gerivá, jeribá, jerivá.

Planta com 10-15 m alt. Estipe 30-40 cm de diâmetro, solitário. Folhas 10-13; bainha 40-60 cm compr., aberta; pecíolo 40-45 cm compr.; raque 2,5-3,2 m compr.; pinas 147-165 em cada lado da folha, dispostas em planos variados, agrupadas na raque em feixes de 2-5 pinas, linear-lanceoladas, caracteristicamente dobradas na porção distal sob um ângulo de aproximadamente $90^{\circ}$, discolores. Inflorescência hermafrodita interfoliar, geralmente 2 por folha; bráctea peduncular 1-1,7 $\mathrm{m}$ de compr., lenhosa; raque
90-125 cm compr.; ráquilas 80-200. Flores estaminadas com sépalas e pétalas coriáceas, com glândulas alaranjadas bem visíveis; estames 6; filete $10-15 \mathrm{~mm}$ compr.; antera ca. $5 \mathrm{~mm}$ de compr.; pistilódio rudimentar. Flores pistiladas ca. 5-6 mm compr.; ovário semi-globoso, tomentoso; estaminódios unidos formando um anel. Fruto 2-3×1,2-2 cm, globoso a ovóide, laranja quando maduro. Semente 1; endosperma homogêneo.

Distribuição e ecologia: ocorre em todos os Estados costeiros desde o Ceará até o Rio Grande do Sul, interiorizando-se em Mato grosso e Minas Gerais. Ocorre ainda na Argentina, Paraguai e Uruguai, espalhando-se por diversos tipos de mata, mas nunca nos cerrados ou na caatinga (Barbosa-Rodrigues 1879; 1898; 1903; Duarte 1981; Glassman 1987; Henderson et al. 1995). No Rio de Janeiro pode ser observada em quase todas as restingas e demais ecossistemas associados às baixadas ou aos costões rochosos, no continente e nas ilhas. Nas encostas de mata atlântica ocorre de modo mais esporádico.

$\mathrm{Na}$ restinga esta espécie ocorre nas matas, sendo mais comum na faixa marginal da mata de primeiro cordão arenoso. Syagrus romanzoffiana está sempre associada a trechos de mata não inundada ou que inundam muito pouco e durante um curto período. Suas folhas podem ser vistas ao longe, pois quase sempre são emergentes no dossel. No segundo e demais cordões de mata ocorrem apenas alguns indivíduos isolados. No primeiro cordão, é, após Allagoptera arenaria, a palmeira de ocorrência mais constante.

Segundo Barbosa-Rodrigues (1903), esta é uma palmeira de grande plasticidade fenotípica, apresentando variações principalmente na forma e nas dimensões do caule, chegando a apresentar alguns exemplares com o estipe ramificado, fato raro nas palmeiras em geral.

Material selecionado: BRASIL. Rio de Janeiro: Maricá, 23/V/1985, R. Andreata 699 et al. (RB); Saquarema, 20/XI/99, fl.fr., R.C.C. Reis 197 et al. (R).

\section{Agradecimentos}

Agradeço ao saudoso Prof. Dr. Luiz Emygdio de Mello Filho, in memoriam, pela orientação; agradeço a CAPES pelo auxílio de bolsa concedido durante o mestrado; agradeço ao amigo e colaborador João Marcelo de Alvarenga Braga, pela correção meticulosa das primeiras versões; agradeço, por fim, ao Prof. Dr. Renato Goldenberg pela forma atenciosa como revisou este trabalho. 

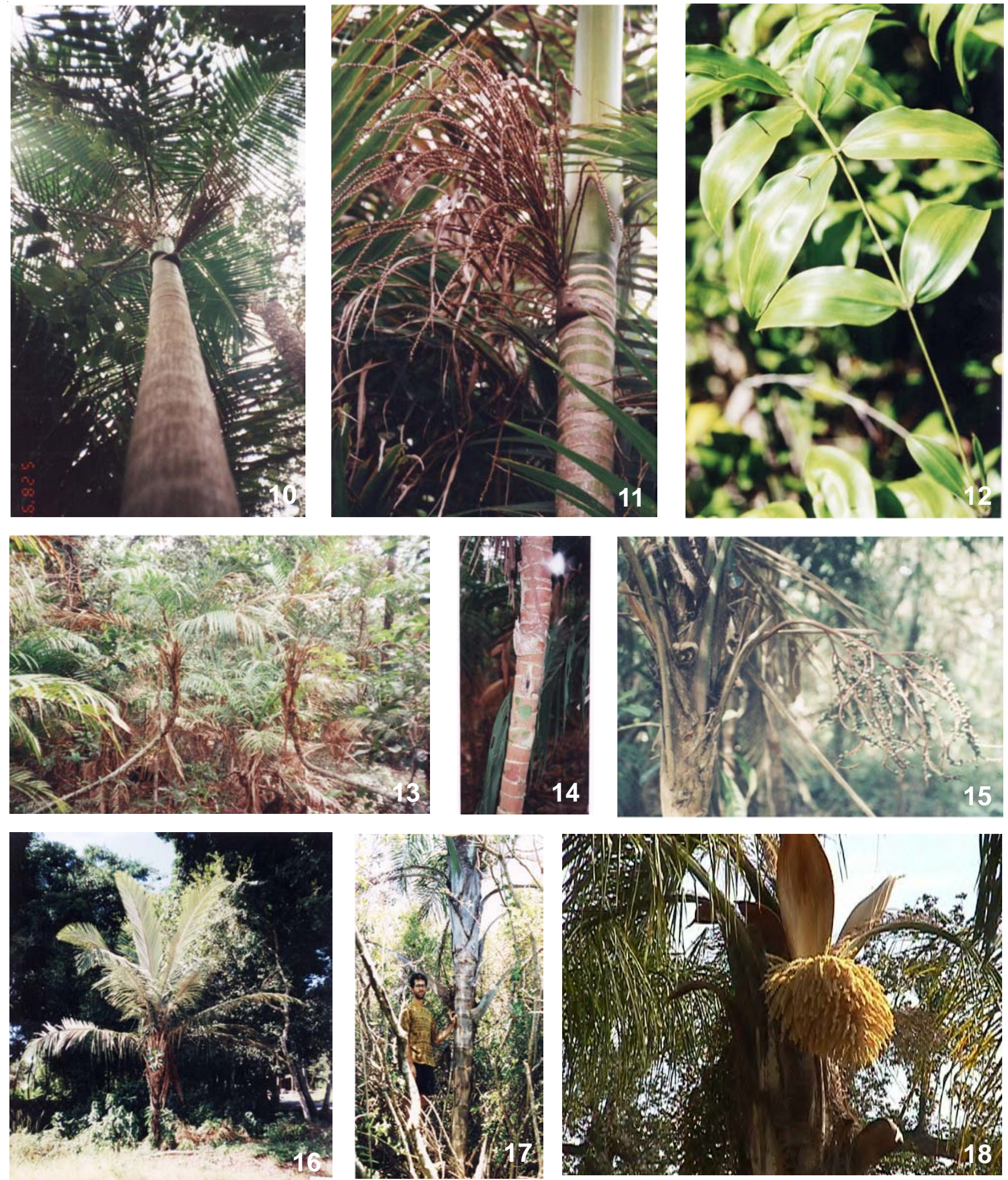

Figuras 10-11. Euterpe edulis Mart. 10. Indivíduo adulto no interior da mata do $2^{\circ}$ cordão arenoso, Carapebus (PNRJ). 11 . Detalhe do eixo da inflorescência (final da frutificação). Figura 12. Desmoncus orthacanthos Mart. Detalhe de uma folha com um cirro provido de acantófilos. Figuras 13-15. Geonoma schottiana Mart. 13. População no sub-bosque de um pequeno remanescente de mata, Quissamã, RJ. 14. Detalhe do estipe. 15. Detalhe do ramo frutífero. Figura 16. Polyandrococos caudescens (Mart.) Barb. Rodr. Indivíduo exposto ao sol em um trecho de mata de restinga degradada, Cabo Frio, RJ. Figuras 17-18. Syagrus romanzoffiana (Cham.) Glassman. 17. Estipe de um indivíduo emergindo em meio a densa vegetação da mata do $1^{\circ}$ cordão arenoso, Maricá, RJ. 18. Detalhe da inflorescência. 


\section{Referências bibliográficas}

Araújo, D.S.D.; Costa, A.F.; Oliveira, A.S. \& Moura, R.L. 2001. Florística e Padrões Fitogeográficos. Pp. 155-165. In: A.F. Costa \& I.C.A. Dias (eds.). Flora do Parque Nacional da Restinga de Jurubatiba e arredores, Rio de Janeiro, Brasil: listagem, florística e fitogeografia. Rio de Janeiro, Universidade Federal do Rio de Janeiro/ Museu Nacional.

Araújo, D.S.D. \& Henriques, R.P.B. 1984. Análise florística das restingas do Estado do Rio de Janeiro. Pp. 159-193. In: L.D. Lacerda; D.S.D. Araujo; B. Turq \& R. Cerqueira (eds.). Restingas: origem, estrutura, processos. Niterói, CEUFF.

Araújo, D.S.D. \& Lacerda, L.D. 1987. A natureza das restingas. Ciência Hoje 6(33): 26-32.

Araújo, D.S.D. \& Maciel, N.C. 1998. Restingas Fluminenses: Biodiversidade e Preservação. Boletim FBCN 25: 27-71.

Araújo, D.S.D. \& Peixoto, A.L. 1977. Renovação da comunidade vegetal de restinga após uma queimada. Pp. 1-18. In: Trabalhos do XXVI Congresso Nacional de Botânica. Rio de Janeiro 1975. Rio de Janeiro, Academia Brasileira de Ciências.

Araújo, D.S.D.; Scarano, F.R; Sá, C.F.C.; Kurtz, B.C.; Zaluar, H.L.T.; Montezuma, R.C.M. \& Oliveira, R.C. 1998. Comunidades Vegetais do Parque Nacional da Restinga de Jurubatiba. Pp. 39-62. In: F.A. Esteves (ed.). Ecologia das Lagoas Costeiras do Parque Nacional da Restinga de Jurubatiba e do Município de Macaé (RJ). Rio de Janeiro, Universidade Federal do Rio de Janeiro, NUPEM-UFRJ.

Barbosa-Rodrigues, J. 1879. Protesto-Appendice ao Enumeratio Palmarum Novarum: Lido no Instituto Histórico e Geográfico. Rio de Janeiro, Typographia Nacional.

Barbosa-Rodrigues, J. 1898. Palmae Mattogrossenses novae vel minus cognitae. Rio de Janeiro, Typographia Leuzinger.

Barbosa-Rodrigues, J. 1901. Palmae-Polyandrococos. Contribuitions du Jardin Botanique du Rio de Janeiro 1: 7-17.

Barbosa Rodrigues, J. 1903. Sertum Palmarum Brasiliensium ou Rèlation des Palmiers Noveaux. Bruxelas, Ed. Expressão e Cultura.

Drude, O. 1881-1882. Palmae. Pp. 253-460, est. 61-106 (1881), Pp. 461-610, est. 107-134 (1882) In: C.F.P. Martius; A.W. Eichler \& I. Urban (eds.). Flora Brasiliensis v. 3, part. 2. München.
Duarte, A.P. 1981. Palmeiras que crescem no estado do Rio de Janeiro. Rodriguésia 33(56): 71-89.

Fernandes, H.B. 1984. Palmae do estado do Rio de Janeiro. Lista das espécies espontâneas e cultivadas. Atas da Sociedade Botânica do Brasil 2(11): 81-86.

Glassman, S.F. 1987. Revisions of the Palm Genus Syagrus Mart. and other selected genera in the Cocos alliance. Urbana, University of Illinois Press.

Glassman, S.F. 1999. A taxonomic treatment of the palm subtribe Attaleinae (tribe Cocoeae). Urbana, University of Illinois press.

Henderson, A. 1995. The Palms of the Amazon. New York, Oxford University Press.

Henderson, A. 2000. Bactris (Palmae). New York, The New York Botanical Garden.

Henderson, A. \& Galeano, G. 1996. Euterpe, Prestoea, and Neonicholsonia (Palmae). New York, The New York Botanical Garden.

Henderson, A.; Galeano, G. \& Bernal, R. 1995. A Field Guide to the Palms of the Americas. New Jersey, Princeton University.

Lorenzi, H.; Souza, H.M.; Medeiros-Costa, J.T.; Cerqueira, L.S.C. \& Ferreira, E. 2004. Palmeiras brasileiras e exóticas cultivadas. São Paulo, Ed. Plantarum Ltda.

Martius, C.F.P. 1823-1850. Historia Naturalis Palmarum: opus tripartitum. Lipsiae. T.O. Weigel.

Mattos, M.D.L. \& Mattos, C.C.L.V. 1976. Palmito Juçara Euterpe edulis Mart. (Palmae) - uma espécie a plantar, manejar e proteger. Brasil Florestal 7(27): 9-20.

Moraes, M.R. 1996. Allagoptera (Palmae). New York, The New York Botanical Garden.

Reitz, P.R. 1974. Palmeiras. In: P.R. Reitz (ed.). Flora Ilustrada Catarinense. Santa Catarina, Herbário Barbosa Rodrigues.

Uhl, N.W. \& Dransfield, J. 1987. Genera Palmarum - a classification of palms based on the work of Harold $E$. Moore Jr. Lawrence, The L.H. Bailey Hortorium \& The International Palm Society.

Ule, E. 1901. Die vegetation von Cabo Frio an der kuste von Brasilien. Botanisches Jahrbucher Systematyk, Pflanzengeschichte und pflanzengeographie 28: 511-28.

Veloso, H.P.; Filho, A.L.R.R. \& Lima, J.C.A. 1991. Classificação da vegetação brasileira, adaptada a um sistema universal. Rio de Janeiro, IBGE.

Wessels Boer, J.G. 1965. The Indigenous Palms of Suriname. Leiden, E.J. Brill. 